\title{
CORRECTION
}

Ivan P. Christov $D$

\section{Correction To: Spatial Non-locality in Confined Quantum Systems: A Liaison with Quantum Correlations}

Published online: 12 November 2020

(C) Springer-Verlag GmbH Austria, part of Springer Nature 2020

\section{Correction To: Few-Body Syst (2020) 61:45 \\ https://doi.org/10.1007/s00601-020-01579-9}

Unfortunately during proofing, corrections to equations 5 and 6 have not been incorporated into the final version before online publication as requested by author. The corrected version of equations 5 and 6 updated here.

Equation 5:

$$
\mathbf{v}_{i}^{k}(t)=\frac{\hbar}{m_{i}} \operatorname{Im}\left[\frac{\nabla_{i} \varphi_{i}^{k}\left(\mathbf{r}_{i}, t\right)}{\varphi_{i}^{k}\left(\mathbf{r}_{i}, t\right)}\right]_{\mathbf{r}_{i}=\mathbf{r}_{i}^{k}(t)},
$$

Equation 6:

$$
d \mathbf{r}_{i}^{k}(\tau)=\mathbf{v}_{i}^{D k} d \tau+\eta_{i}(\tau) \sqrt{\frac{\hbar}{m_{i}} d \tau},
$$

The original article has been corrected.

Publisher's Note Springer Nature remains neutral with regard to jurisdictional claims in published maps and institutional affiliations.

I. P. Christov

Institute of Electronics, Bulgarian Academy of Sciences, 1784 Sofia, Bulgaria

I. P. Christov $(\varangle)$

Physics Department, Sofia University, 1164 Sofia, Bulgaria

E-mail: ivan.christov@phys.uni-sofia.bg 